\title{
Carcinoma adenoescamoso: um estudo de caso em citologia ginecológica
}

\author{
Pote $\mathrm{A}^{1}$, Sousa $\mathrm{R}^{2}$, Mendonça $\mathrm{P}^{1}$ \\ ${ }^{1}$ Instituto Politécnico de Lisboa, Escola Superior de Tecnologia da Saúde de Lisboa \\ ${ }^{2}$ Hospital da Luz, Lisboa, Portugal
}

Recebido: março 2018/ Publicado: dezembro 2018

https://doi.org/10.26537/citotech.v0i4.3013

\section{*Autor correspondente:}

Alexandra Pote

alexandrapote@hotmail.com

\section{RESUMO}

O carcinoma adenoescamoso é um tumor raro que representa cerca de $4 \%$ dos tumores cervicais. Este carcinoma ocorre maioritariamente em mulheres com cerca de 50 anos, podendo ocorrer em mulheres mais jovens e está também associado ao estado de gravidez e à infeção pelo Papiloma Vírus Humano.

No presente trabalho, relata-se o caso de uma mulher de 45 anos, com coitorragias e uma lesão dura, elevada e hemorrágica no colo do útero, que foi submetida a citologia esfoliativa. $O$ exame microscópico permitiu visualizar achados citológicos compatíveis com coexistência de componente pavimentosa- células pleomórficas com citoplasma denso com aumento da relação núcleo citoplasma e componente glandular- pseudoestratificação, feathering e núcleos alongados. O relatório citológico foi de carcinoma pavimento celular, não excluindo a possibilidade de carcinoma adenoescamoso.

No seguimento da doente, foi realizada biópsia ao colo uterino, cujo diagnóstico histológico foi de adenocarcinoma invasor produtor de muco com uma componente do tipo pavimentoso. Esta neoplasia faz diagnóstico diferencial principalmente com "tumores de colisão" onde ocorrem duas neoplasias primárias, uma glandular e outra pavimentosa.

Para este tipo de tumor, a interpretação citológica pode ser desafiante, pela dificuldade de interpretar nos aspetos citomorfológicos a componente pavimentosa e glandular na mesma amostra.

Palavras-chave: Carcinoma adenoescamoso; Colo uterino; Citologia ginecológica. 


\section{APRESENTAÇÃO DO CASO}

No presente trabalho relata-se 0 caso clínico de uma mulher de 45 anos, cuja informação clínica relata coitarragias e observação de uma lesão dura elevada e hemorrágica do colo do útero. É feito um pedido de citologia urgente.

A amostra citológica foi processada pelo equipamento ThinPrep5000®, sendo posteriormente corada com a coloração de Papanicolaou.

No exame microscópico, foram observados grupos de células pleomórficas, anisocariose, cromatina grosseira mal distribuída, aumento da relação núcleocitoplasma, hipercromasia e diátese tumoral, sendo estas características associadas a aspetos malignos $^{1-4}$ (Fig.1A e Fig.1B).
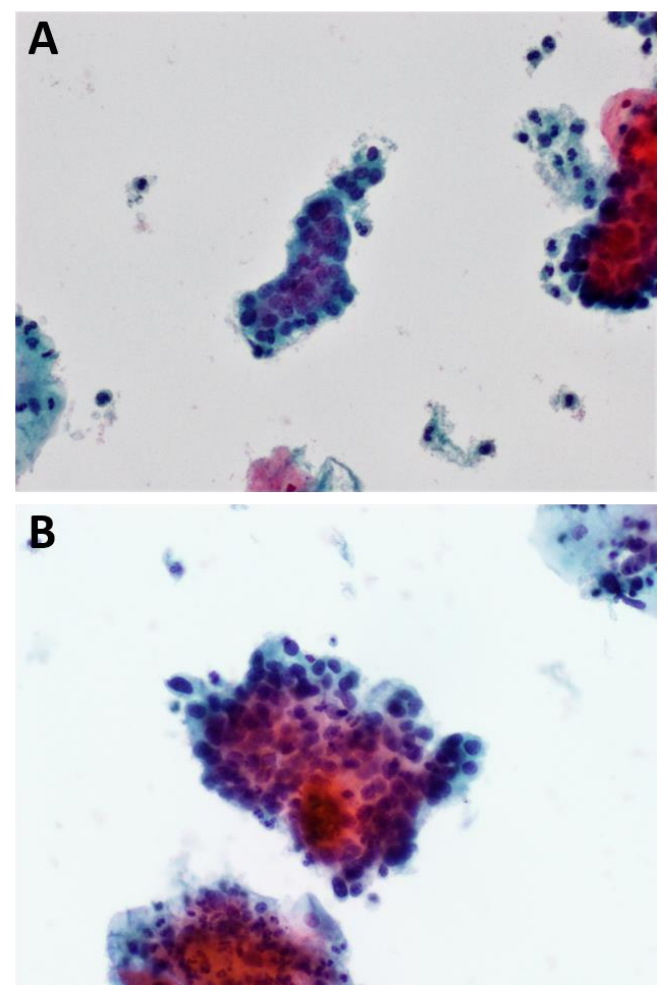

Fig.1 - Em A e B observam-se agrupamentos celulares atípico com células pleomórficas, cromatina grosseira e mal distribuída, e diátese tumoral. Citologia em meio líquido (ThinPrep®), coloração de Papanicolaou, ampliação 20x.
Na observação microscópica da amostra citológica, foram encontrados diversos agregados com células pleomórficas de citoplasma denso, limites mal definidos, com aumento da relação núcleo-citoplasma e hipercromasia, cromatina grosseira mal distribuída e presença de diátese tumoral (Fig.2A e Fig.2B), estas características observadas estão associadas a carcinoma pavimento celular, indicando a presença de um componente pavimentoso ${ }^{1-4}$.
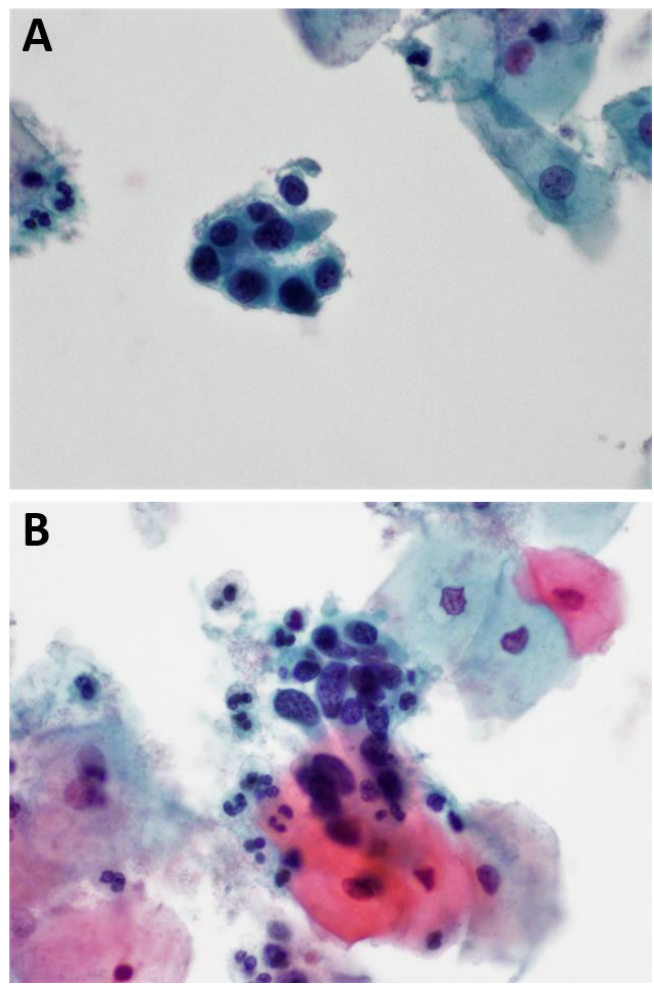

Fig.2 - Em A e B observam-se dois agrupamentos celulares com características de carcinoma pavimento-celular, onde se evidenciam células pleomórficas de citoplasma denso, limites mal definidos, com aumento da relação núcleocitoplasma e hipercromasia. Citologia em meio líquido (ThinPrep®), coloração de Papanicolaou, ampliação 40x.

Observou-se, ainda, a presença de células em agregados com os contornos celulares mal definidos e organizadas em paliçada, com pseudo-estratificação e perda de polaridade. Os núcleos estão alongados, em 
forma de charuto, havendo um aumento da relação núcleo-citoplasma. Verificou-se, ainda, grupos de células com feathering, sobreposição e apinhamento dos núcleos. Foram ainda visualizados grupos com células sobrepostas, com núcleos redondos/ovais aumentados, membrana nuclear irregular, cromatina granular mal distribuída e nucléolo proeminente (Fig.3A, Fig.3B e Fig.3C).
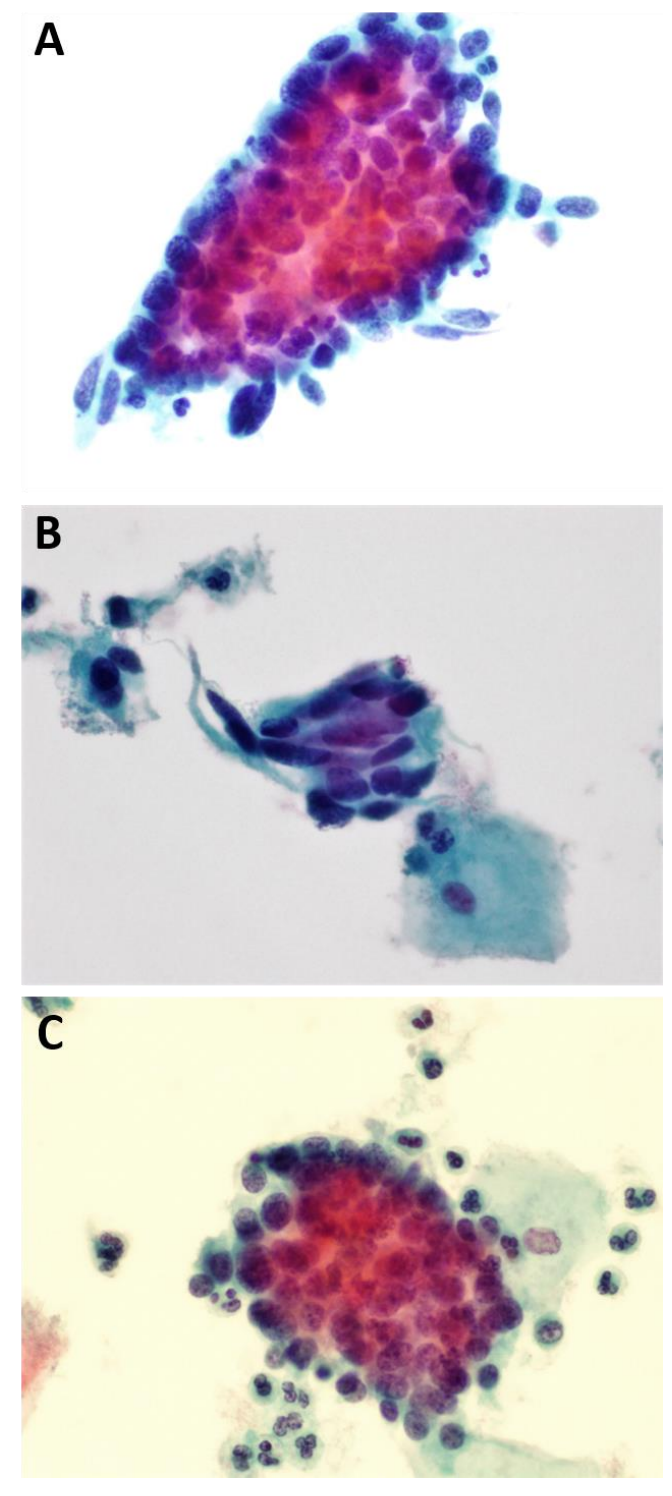

Fig.3 - Agrupamentos celulares com características de adenocarcinoma, evidenciando-se a presença de células com pseudoestratificação, perda de polaridade e cromatina granular mal distribuída. Observam-se alguns núcleos alongados, assim como agrupamentos celulares com feathering (A e B) e nucléolo proeminente (C). Citologia em meio líquido (ThinPrep®), coloração de Papanicolaou, ampliação 40x.
Os agrupamentos mencionados apresentam particularidades que estão associadas a adenocarcinoma indicando a presença de um componente glandular ${ }^{1-4}$.

No seguimento deste resultado realizouse uma biópsia do colo uterino, com vários fragmentos que foram posteriormente fixadas em formol e posteriormente processados Tissue-Tek Xpress $\AA^{\circledR} \times 120$, incluídos em parafina e corados com hematoxilina-eosina (HE).

O diagnóstico histológico (Fig.4) indica a presença de uma neoplasia epitelial maligna, mais especificamente um adenocarcinoma invasivo produtor de muco, visualizando-se a presença de mucinas, mas com presença de uma componente do tipo pavimentoso.

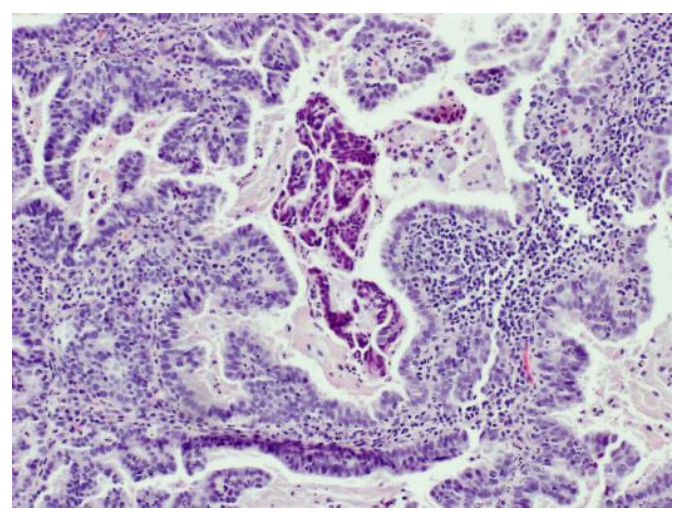

Fig.4 - Representação histológica de colo uterino com carcinoma adenoescamoso, de variante mucinosa. Coloração de hematoxilina-eosina, ampliação 20x.

\section{PROPOSTA INICIAL DE DIAGNÓSTICO}

De acordo com as características encontradas, o diagnóstico foi de carcinoma pavimento celular, não se podendo excluir a possibilidade de se tratar de um carcinoma adenoescamoso.

\section{ANÁLISE E DISCUSSÃO DO CASO}

O carcinoma adenoescamoso é um tumor raro, correspondendo a $4 \%$ dos tumores cervicais, e tem origem nas células de reserva subcolunares. Pode ocorrer tanto em mulheres jovens como em mulheres mais velhas, sendo 
a idade média 57 anos. Está frequentemente associado à gravidez. Os fatores de risco são os mesmos que estão associados ao carcinoma pavimento celular e ao adenocarcinoma: hábitos tabágicos, múltiplos parceiros sexuais e presença de HPV 16 e 18. Pode apresentar um aspeto polipoide, ulceroso ou nodular. O carcinoma adenoescamoso, quando comparado com adenocarcinoma, é mais indiferenciado e tem uma maior probabilidade de invasão vascular. Quanto ao prognóstico, de acordo com a literatura, a variante mucinosa tem um pior prognóstico que os restantes carcinomas do colo do útero, tendo uma previsão de 5 anos de sobrevivência em qualquer estadio 1,3,5-11. Em citologia, é comum a existência de aspetos malignos da componente pavimentosa e glandular, bem como a presença de diátese tumoral. Os achados citológicos incluem células em agregados sinciais, núcleos redondos a ovais com diferença de tamanho, nucléolo proeminente e cromatina granular e com distribuição irregular8,9,10.

As características citológicas observadas neste caso sugeriram resultados citológicos tanto de carcinoma pavimento celular como de adenocarcinoma. No entanto, esta colpocitologia, em relatório citológico, foi relatada como um carcinoma pavimento celular, uma vez que se trata de uma mulher de 45 anos que não se encontra na menopausa. Segundo a literatura, os 60 anos é a idade mais comum para o aparecimento de adenocarcinoma, sendo que o patologista fez a observação de que possivelmente seria um carcinoma adenoescamoso, uma vez que a presença de células pavimentosas e glandulares malignas sugere este diagnóstico $0^{1,5,6,7}$.

O diagnóstico de carcinoma adenoescamoso é feito quando se observa diferenciação pavimentosa e diferenciação glandular histologicamente, sendo que cada elemento deve ser bem visível em HE, sem necessidade de recorrer a colorações especiais. De acordo com a literatura, para se reportar uma diferenciação pavimentosa, devem estar presentes pelo menos uma das seguintes características: pontes intercelulares, pérolas de queratina e mórulas de "spindle cells,", células poligonais com citoplasma eosinófilo1,3,5. A componente glandular é normalmente do tipo endocervical, mas pode ser endometrial, de células claras,ou do tipo mucinoso, como neste caso. O tipo mucinoso é uma variante menos comum. Histologicamente, apresenta-se com um aspeto indiferenciado, com um citoplasma eosinofílico finamente granular, com bordos angulares, núcleos grandes e vesiculosos, nucléolo proeminente e mitoses frequentes ${ }^{1,3,5-}$ 11.

O diagnóstico histológico foi de adenocarcinoma invasivo produtor de muco com presença de componente do tipo pavimentoso. Esta descrição corroborou a diferenciação do tipo pavimentosa da neoplasia. $\mathrm{Na}$ literatura, está descrito que em casos de carcinoma adenoescamoso, a presença de elementos com diferenciação pavimentosa maligna com associação de células glandulares com características de malignidade, o que está presente neste caso, sugerindo um pior prognóstico ${ }^{1,5-7}$.

A entidade descrita faz diagnóstico diferencial com "tumores de colisão ", onde existem duas neoplasias distintas, uma de componente pavimentosa e outra glandular. No carcinoma adenoescamoso, estas duas componentes estão misturadas, em conjunto. Faz também diagnostico diferencial com carcinoma adenoide basal, sendo possível distingui-los uma vez que este último apresenta células uniformes e com escasso citoplasma e alterações nucleares pouco proeminentes. Para se compreender a extensão e gravidade deste tipo lesão, sugerese conização ou histerectomia6-11. 


\section{CONCLUSÃO}

Através da colpocitologia foi possível um resultado citológico de carcinoma pavimentocelular, não se podendo excluir a possibilidade de se tratar de um carcinoma adenoescamoso. Em exame citológico, foram observadas características de malignidade em células de componente pavimentosa e glandular. Contudo, apenas histologicamente foi dado um diagnóstico adenocarcinoma invasivo produtor de muco com presença de componente do tipo pavimentoso, por estarem reunidos todos os achados característicos desta patologia.

\section{REFERÊNCIAS BIBLIOGRÁFICAS}

1. Cibas E, Ducatman B. Cytology: Diagnostic Principles and Clinical Correlates. 3 ed. China: Saunders; 2009.

2. DeMay R. The Art \& Science of Cytopathology. vol. 1. Chicago: ASCPPress; 1996.

3. Gray W, Kocjan G. Diagnostic cytopathology. 3rd ed. Churchill Livingstone Elsevier; 2010.

4. Koss L. Diagnostic cytology and its histopathologic bases. vol. I,II. 6th ed. Philadelphia: J.B.Lippincott; 2006.

5. Kurman RJ, Ronnett BM, Sherman ME, Wilkinson EJ. Tumors of the Cervix, Vagina, and Vulva. 1st ed. Washigton,DC: American Registry of Pathology; 2010.

6. Lim C, Leecy T, McKenzie P, Pather S, Carter $J$, Russell P. Two cases of adenosquamous carcinoma of the cervix with extensive in situ and invasive endometrial extension. Int J Gynecol Pathol 2011;30:193-7. doi:10.1097/PGP.0b013e3181fceffc.

7. Marluce Bibbo, Wilbur D. Comprehensive cytopathology. 3rd ed. Philadelphia: Saunders Elsevier; 2008.

8. Mutter GL, Prat J. Pathology of the female reproductive tract. 3 rd ed. Churchill Livingstone Elsevier; 2014.

9. Nucci MR, Oliva E. Gynecologic Pathology 1st Edition. 1st ed. Churchill Livingstone Elsevier; 2009.

10. Ohta $Y$, Kunimura T, Omatsu M, Shiokawa A, Kushima M, Ota H. Mixed mucin-producing and squamous differentiated tumor of the uterine cervix: a report of a case as adenosquamous carcinoma in situ. J Obstet Gynaecol Res 2013;39:420-3. doi:10.1111/j.14470756.2012.01904.x.

11. Zaino RJ, Kurman R, Herbold D, Gliedman J, Bundy BN, Voet R, et al. The significance of squamous differentiation in endometrial carcinoma. Data from a gynecologic oncology group study. Cancer 1991;68:2293-302. doi:10.1002/10970142(19911115)68:10<2293::AIDCNCR2820681032>3.0.CO;2-V 